\section{NARRACIONES ESPAÑOLAS DEL FIN DEL MUNDO I. LAS NOVELAS LAICAS}

\author{
Agustín Jaureguízar \\ Doctor Ingeniero de Caminos
}

Periodista

\begin{abstract}
Novels about the End of Time are quite usual in many countries' literary body of work, but not so in Spain. These novels are narratives in which the author will put Mankind under judgment before making it disappear. It is most common, based on a principle of unlimited progress of civilization, that this idea will eventually give way to argue the opposite, and therefore the big question arises: Does Mankind perish by accident or because of their actions? In the two novels we shall review, it is bound to perish by misfortune, although in one of them it does occur, being an exceptional case, that the collective effort of all of humanity will avert catastrophe.
\end{abstract}

KEY WORDS: N. Tassin; José Lión-Dépêtre; Narraciones del fin del mundo (World's ending narratives); La catástrofe (The catastrophe); Zootauros de Marte (Mars' zootaurs); Un mundo subterráneo (Underground world); Las confesiones de Cayac-Hamuaca (Confessions of Cayac-Hamuaca); El sol muerto (A dead sun); La Tierra congelada (Frozen Earth).

Quien diga con Borges que los géneros crean sus propios precursores, podrá decir que las narraciones del fin del mundo se remontan a una lejana antigüedad, recogidas en los textos sagrados de diversas religiones antes que en textos profanos.

Como a su vez señalan Clute y Nicholls, hay tres temas que se repiten en la literatura fantástica pre-siglo XX, las utopías, los cuentos aleccionadores o de escarmiento y las visiones apocalípticas del fin del mundo que, con el paso de los años y los mayores conocimientos científicos, fueron abandonando el ámbito de lo sagrado para penetrar en el de lo profano.

Renunciando a precedentes rebuscados, hay que empezar por decir que el francés Jean-Baptiste Grainville escribió en 1805 Le dernier homme, una obra que es piedra miliar del género para Versins. En ella el autor encuentra al Tiempo encadenado en una profunda caverna próxima a Palmira

\section{SPANISH STORIES ON THE END OF THE WORLD \\ I. THE SECULAR NOVELS}

RESUMEN: Las novelas del fin de los tiempos son frecuentes en las literaturas de muchos países, que se han preocupado de darlas a conocer, no así en España. Son narraciones en las que el autor se compromete a enjuiciar a la Humanidad que va a hacer desaparecer. Es lo más común que, partiendo en principio de un progreso sin límites de la civilización, esta idea termine por dar paso a la contraria y surja la gran pregunta: ¿La Humanidad perece por azar 0 como consecuencia de sus actos? En las dos novelas que reseñamos está llamada a perecer por infortunio, aunque en una se dé el caso excepcional de que el esfuerzo colectivo de la Humanidad entera va a evitar la catástrofe.

PALABRAS CLAVE: N. Tassin; José Lión-Dépêtre; Narraciones del fin del mundo; La catástrofe; Zootauros de Marte; Un mundo subterráneo; Las confesiones de Cayac-Hamuaca; El sol muerto; La Tierra congelada.

y éste le desvela el porvenir para que quede memoria del último hombre sobre la Tierra. No será el último, sin embargo, porque intervendrá el Genio de la Tierra para anunciarle que en Brasil hay una joven con la que podrá procrear y dar vida a una nueva Humanidad.

Dentro del dominio de la ciencia ficción, son muchos los que entienden que la primera novela de la estirpe fue el Frankenstein de Mary Shelley, publicado en 1818. La misma autora escribió ocho años después The Last Man, donde el último hombre sobre la Tierra es realmente el último: tras una mortal epidemia de peste, el 1 de enero de 2110 graba desde su barca esta fecha en la cúpula de San Pedro, cuyo nivel han alcanzado las aguas, y se dispone a esperar la muerte. Al igual que la anterior, es una obra no traducida al castellano.

Sí está múltiplemente vertida a nuestra lengua La máquina del tiempo de Wells, en la que el Viajero a través del tiempo remata su periplo en un futuro remoto en el que la Tie- 

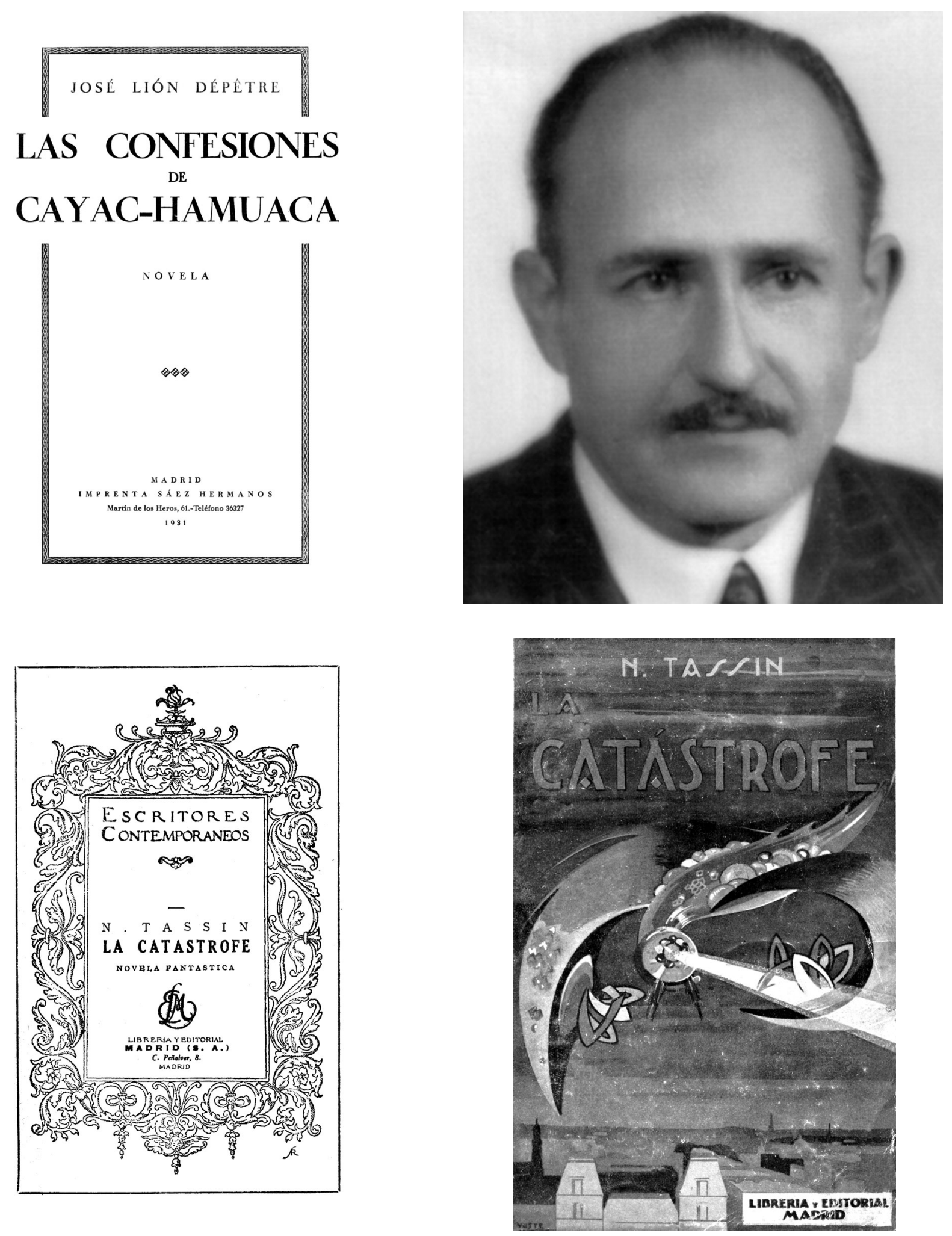
rra está sumida en un eterno crepúsculo gris, despoblada de todo vestigio humano y habitada por unos cangrejos inmundos que se arrastran hacia el viajero provocando sus náuseas. La sensación de abominación atroz que lo sobrecoge nos transmite un fin del mundo que pocos han podido igualar.

En estas novelas el autor se compromete, obligado a enjuiciar a la Humanidad que va a hacer desaparecer. Partiendo en principio de un progreso sin límites de la civilización, esta idea termina por dar paso a la contraria y surge la gran pregunta: ¿La Humanidad perece por azar o infortunio, o como consecuencia de sus actos?

Se van escribiendo obras tan interesantes como La nube purpúrea de Shiel en 1901 o La peste escarlata de London en 1915, por poner bien conocidos ejemplos, hasta llegar a esa obra impar del declinar de la civilización que es $L a$ Tierra permanece de Stewart en 1949, con la que guarda semejanza la reciente La carretera de McCarthy.

La lista sería muy larga, entre otras con Barbagris de Brian Aldiss, La hora final de Nevil Shute, La gente del margen de Orson Scott Card y esa joya olvidada por la perestroika que es La última nave de William Brinkley en 1988. Algunas de ellas se han llevado a la pantalla y son las más conocidas del gran público.

Una división comúnmente aceptada para estas novelas atiende a las causas de la destrucción del mundo, que pueden ser un accidente, una epidemia, la degeneración biológica de la especie humana, un cataclismo cósmico o nuclear entre las ordinarias y un castigo divino u originado por una raza extraterrestre entre las extraordinarias.

Otra es la que diferencia aquellas historias en las que la Humanidad realmente se extingue de aquellas otras en que se salva un reducido grupo de hombres y mujeres, en ocasiones una sola pareja que dará origen a una raza nueva, de valores morales superiores a los de la desaparecida. Unas pocas veces, como en la novela que comento a continuación, es la Humanidad entera la que colectiva y solidariamente se enfrenta a la destrucción que la amenaza y consigue acabar con ella para sobrevivir.

Como ya he apuntado, hubieron de transcurrir siglos antes de que esta literatura pasara del ámbito de lo sagrado al de lo profano. Empezó escribiéndose en el siglo XIX en Inglaterra y en Francia, naciones en las que proliferó abundante desde el inicio del XX. Algunos años más hubieron de transcurrir en España para que se escribieran las primeras narraciones del género que, como se ha hecho en otros países, es de justicia rescatar del olvido en que están sumidas. La mejor fue La catástrofe de Tassin ${ }^{1}$.

"En la sesión extraordinaria de la Academia Francesa, celebrada el 27 de marzo de 1967, fueron designados con el nombre de zootauros". Así comienza su novela N. Tassin, que era frecuente que abreviara su nombre de Nicolás a su inicial, pero que sólo en esta obra aparece con su apellido escrito con dos eses, quizá por error.

Son pocas las referencias que hacen a él los libros de consulta. Escriben Pedraza y Rodríguez Cáceres: "También se suma a la causa revolucionaria Biblioteca Nueva [...] Publica una serie histórica sobre la revolución rusa escrita por Nicolás Tasin. Esta serie la compusieron La revolución rusa (1919), La dictadura del proletariado (1920) y Héroes y mártires de la revolución rusa (1921), a más de varias traducciones de los clásicos de la Revolución que hizo el mismo Tasin.

Uno de estos libros incluye algunos datos biográficos suyos, muy genéricos, que no dicen ni que Tasin era un seudónimo ni dónde y cuándo nació y exageran su relevancia histórica, pues no es cierto que fuera amigo personal de Trotsky ni de Lenin ${ }^{3}$. Eso es todo cuanto en principio supe de él y he de agradecer sus datos biográficos reales a la amabilidad del segundo secretario de la Embajada de la Federación Rusa en Madrid, el señor Mijail Rossiyski, y a la señora Tatiana Korolkova, de Moscú ${ }^{4}$.

El judío ruso Naum Yákovlevich Kagan nació el 8 de abril de 1874. Activista político de ideología socialdemócrata, fue condenado a trabajos forzados en Yakutsk, consiguiendo evadirse en 1907 y exilarse en Francia. Colaboró en algunos periódicos rusos y conoció a M. S. Milrud, del diario Segodnia (Hoy), de Riga, en el que después escribiría. Pasó la guerra en la capital gala, dándose a conocer por sus relatos militares reunidos en el libro En la Francia combatiente. Editó el periódico pacifista de izquierdas Ótkilki (Ecos), que terminó siendo cerrado y Tasin expulsado del país creo que en 1917, todo lo más a principios de 1918.

ARBOR Vol. 187747 enero-febrero [2011] 183-194 ISSN: 0210-1963 
Pasó entonces a España, donde pronto acreditó el buen dominio de la lengua que demuestra en sus colaboraciones periodisticas, de un modo particular en El Sol, y en sus traducciones al castellano, versiones de los clásicos rusos que aún se siguen editando. Publicó en Madrid las tres novelas antes citadas más La catástrofe, de modo que lo mejor de su vida de escritor lo dio en España y en español. Tras adoptar el nombre definitivo de Naum Tasin Kagan, al cabo de bastantes años de estancia entre nosotros abandonó Madrid para trasladarse a Viena, donde contrajo matrimonio con una mujer no judía, una alemana de Dantzig llamada Amalia, catorce años más joven que él. No mucho después, cuando los nazis se anexionaron Austria en 1938, su firma desapareció de los periódicos y se le fijó su residencia en Liepaja (Letonia), donde fue muerto en 1941, ignorándose la suerte que corrió su mujer, aunque sí parece que le sobrevivió su hijo Alexander Abel.

Fue nuestro autor difusamente español, aunque reitero que lo más y mejor de su producción lo escribió aquí y en nuestro idioma: los pocos que mencionan La catástrofe la incluyen en la bibliografía nacional del género cientificticio. Es poco sabido que conoció una primera versión en Berlín, Katastrofa, no publicada en Rusia por lo que supongo motivos políticos, mas el propio autor la reescribió enteramente en español, expandiéndola hasta cerca del doble de su extensión original cuando residía y publicaba en España y española la consideraron las críticas que mereció en su momento en nuestro pais: es una novela de ciencia ficción moderna, como ninguno de los nuestros había escrito antes, sin que su adscripción diga nada en pro o en contra de su interés.

Su acción principal se desarrolla en París, ciudad bien conocida de Tassin, que en la madrugada del 26 al 27 de marzo de $1967^{5}$ es atacada por los seres monstruosos bautizados como zootauros, que vuelven a la noche siguiente dejando un largo reguero de víctimas y destrozos: catorce mil muertos y centenares de casas destruidas, así como la estación del Norte, que es materialmente arrasada cuando está llena de gente.

En medio de la confusión y el pánico generalizados, llegan noticias de pérdidas semejantes en Londres, Berlín, Madrid y Nueva York, donde los muertos superan los 150.000. Muchos de los que se han refugiado en los sótanos han quedado atrapados bajo los escombros y otros han sido agarrados por los zootauros como gavillas, para precipitarlos después desde lo alto.

Miles de personas llegan a la capital en busca de una seguridad que no encuentran, guareciéndose en los edificios públicos por la noche y buscando desesperadamente comida durante el día, lo que sume a la ciudad en una gran confusión, por más que se fusile sobre el terreno a los saqueadores.

"En el curso de la tercera noche sobrevino un acontecimiento propio para provocar la estupefacción aun en los tiempos en que el espanto era el estado de ánimo normal de las gentes": en la plaza de Nôtre-Dame, junto a los restos de la catedral, apareció muerto un zootauro. Medía más de 100 metros de largo y 170 de envergadura, con unas alas que desplegaban cerca de 3.000 metros cuadrados cada una, rematadas por siete garras de metro y medio. Pesaba entre 800 y 900 toneladas y su cuerpo estaba recubierto por un caparazón que no fue posible perforar. A los lados de las alas llevaba 14 excrecencias de gran capacidad que podrían contener el gas que respiraría mientras atravesaba los espacios interplanetarios, pues se decía sin mayores pruebas que procedían de otro mundo, probablemente de Marte ${ }^{6}$.

Poseía dos ojos, uno en la frente y otro en la nuca, que funcionaban como reflectores de gran alcance y serían su único punto vulnerable, pensándose que no se adaptaban a la visión diurna y por eso atacaban de noche. Carecian de nariz y orejas y se comunicaban mediante otros 14 discos de colores que se encendían y apagaban según un código de lenguaje que no se supo descifrar. Este autor ni especula ni establece teorias fantásticas, a partir del catacronismo o el hecho fundador, que dicen los franceses, que supone la aparición de los zootauros, va narrando los acontecimientos en la medida en que con toda lógica se van sucediendo. $\mathrm{Ni}$ qué decir tiene que los zootauros son imagen de los zeppelines alemanes que bombardearon Paris durante la guerra, aparentemente invulnerables ${ }^{7}$. El zootauro caído sobre Nôtre-Dame parece evocar aquel primer zeppelin que cayó en el bosque de Cambray.

A los pocos días, en una reunión de la Academia a la que asisten todos los miembros que no han fallecido, se da cuenta de que un zootauro ha cogido un elefante en el zoológico de París y lo ha dejado caer menos de cuatro mi- 
nutos después en una población situada a 2.200 kilómetros de distancia, lo que permite establecer que su velocidad ha superado los 33.000 kilómetros por hora, cerca de 10 kilómetros por segundo.

En los países del primer mundo se procura mantener la autoridad y el orden posibles, mientras los científicos se afanan por encontrar un medio de combatir a los monstruos, aunque no faltan ni los predicadores de la cólera divina que exhortan a la penitencia, ni las bandas de delincuentes que se entregan al pillaje. En los más atrasados, en cambio, impera el caos, apareciendo en unos sectas que adoran a los nuevos dioses y les ofrecen sacrificios humanos -un reyezuelo africano hace degollar a trescientas de sus seiscientas esposas, para ser víctima él mismo del ataque de esa noche- y convirtiéndose en otros el saqueo en una actividad de Estado, con gobernantes que se suceden sin cuento cuando mueren a manos de quienes aspiran a sucederlos o a garras de zootauros.

Corren rumores disparatados que atienden las muchedumbres aterradas a las que el instinto de conservación les impide estar quietas. Cuando se propala que los zootauros no atacan a los barcos, verdaderas multitudes se dirigen a los puertos, pagando precios desorbitados por los pasajes o tomando al asalto los navíos. $Y$ cosa parecida ocurre después con los aeropuertos, cuando se extiende el rumor de que hay territorios remotos que no son visitados por los monstruos, mas todo es pura invención. Los campesinos aún pueden cultivar los campos de día y tratar de guarecerse en grutas naturales por la noche, mas, a los habitantes de las ciudades, no les cabe ese recurso.

En medio del pánico que cabría esperar, los Estados Unidos de Europa, que están perfectamente organizados como tales, celebran un Consejo extraordinario en el que se toma la decisión de atacar a los zootauros con todas las armas disponibles, descargas eléctricas, proyectiles de gases asfixiantes y de los bacilos de las enfermedades más letales, disparados desde tierra, y bombas explosivas de la mayor potencia arrojadas sobre ellos desde el aire por las fuerzas aéreas coaligadas de Francia, Alemania, Inglaterra, Italia y España. Nunca falta la figura de un español, aquí presente en el jefe de nuestra aviación, el general González Diego, tan afable como enérgico, como demostró en la represión de los últimos disturbios de Barcelona: es una novela española, no habria lugar para González Diego en una rusa.
Ante la expectación de todo París, los zootauros parecen divertirse al principio con los rayos eléctricos, los proyectiles y las bombas que los alcanzan sin producirles el menor efecto, hasta que se cansan del juego, derriban los aviones y se entregan a una devastación como no se había conocido. Al llegar el día la ciudad amanece deshecha y sin fuerzas: Paris agoniza.

La decisión siguiente, tomada en previsión de que la anterior fracasase, es construir una ciudad subterránea a gran profundidad. Otro novelista podría haber rematado enseguida la ya interesante novela, mas Tasin no ha hecho sino iniciarla. Se va a plantear la resolución de un gigantesco proyecto de ingeniería enmarcado en una ambiciosa utopía influida por su visión, que se diría ya un tanto preocupada, hasta desencantada, de la revolución rusa.

El autor, que ha escrito en otro libro que a partir de esa revolución existe "una línea de demarcación entre el viejo mundo y el mundo naciente, entre el régimen capitalista y el socialista", presenta aquí el orden social nuevo: los hombres que han visto la muerte tan de cerca y no albergan otro deseo que el de sobrevivir, van a descender todos iguales bajo tierra, a casas todas iguales ${ }^{8}$, con todos los bienes colectivizados.

Como corresponde a una buena utopía, la ciudad se diseña con el más cuidado y moderno urbanismo, dotada de todas las comodidades que antes tenía y aún más, con magníficos centros de trabajo y espléndidos lugares de esparcimiento, con arte, espectáculos y hasta un lujo racional.

"Seamos socialistas, colectivistas, comunistas o cuanto queráis", dice el Presidente de la Comisión Subterránea, pálido y enflaquecido, a los delegados de una Asamblea sobre la que parece volar el ángel de la muerte. "iSe trata de la salvación del género humano!", y esta salvación no podrá lograrse sin grandes sacrificios, sin igualdad y sin justicia.

El Gobierno francés -el americano hace lo mismo en Nueva York- promulga un decreto de movilización general del trabajo y otro de impuestos progresivos sobre el capital que van del 30 al $80 \%$. Como era de esperar, protestan los anarquistas por la izquierda, que pretenden aprovechar la situación para acabar con el sistema, y protestan los rentistas por la derecha, que no quieren perder su dinero. 
Pero la respuesta general es positiva al divisar por fin las gentes un rayo de esperanza.

Un popular artista va cantando por las calles de Paris, con música de conocidos cuplés, letrillas alusivas al momento, como la que reproduzco, que creo que abona la tesis de que la novela se reescribió para su edición española:

Los zootauros, tauros, tauros,

nos tienen fastidiaos.

Los zootauros, tauros, tauros,

se nos han atravesao.

300.000 obreros inician de inmediato la construcción de una pequeña ciudad de mil casas de seis pisos, que se estima darán cobijo a 150.000 personas, mientras que las necesidades totales de París se cifran en unas cuarenta mil viviendas. El cálculo parte de la hipótesis de que los zootauros acaban cada día con la vida de 6.000 personas en la capital y 40.000 en toda Francia, a las que hay que añadir otras tantas que perecen a causa de la difícil situación por la que atraviesan: con que las cosas sigan así un año, la población gala se verá reducida a la mitad.

La edificación avanza sin pausa y en las afueras van creciendo montañas de tierra excavada, mientras la ciudad es víctima de dos inconvenientes más: por un lado, millones de provincianos se siguen dirigiendo hacia ella, enfrentándose a las tropas que les impiden el paso, con muertos por ambas partes, acampando después a la intemperie, donde son víctimas fáciles de los zootauros, las enfermedades y la inanición; por otra parte, los propios ciudadanos de París se levantan con frecuencia contra el gobierno al dar crédito a falsos rumores, el más insidioso el de que los primeros en descender bajo tierra y ponerse a salvo van a ser los políticos y las personas ricas o influyentes -si es que no son las mismas-.

Mas lo peor está aún por llegar y, como siempre, el autor lo describe con un frío distanciamiento y una precisión aterradora. Los zootauros, que suelen acudir en número de tres o cuatro, llegan una noche a los cuarenta y las muchedumbres, enloquecidas por el pánico más irracional, asaltan la ciudad subterránea en construcción en busca de refugio, auténticamente fuera de control, sin que los soldados que tiran a matar sean capaces de detenerlas. Las entradas se convierten en cuellos de botella en que muchos mueren aplastados; los que consiguen entrar han de descender cerca de tres mil peldaños a pie; los que se detienen producen tapones que llegan hasta el techo, y los que se ven impedidos de proseguir son aplastados por los que les siguen.

Esa noche los zootauros atacan con saña y sus víctimas se cuentan por decenas de millares. Y, por si fuera poco, los provincianos aprovechan que los soldados han tenido que acudir a defender las entradas a la ciudad de abajo para invadir la de arriba, aumentando la confusión. Cuando se evalúan los daños, los muertos ascienden a más de 300.000 .

Los cadáveres han de enterrarse, más la extracción de los que se vieron atrapados en las profundidades es lenta y laboriosa $y_{1}$ en esa atmósfera emponzoñada, una epidemia azota a los supervivientes matando a muchos más. La descripción del horror se extiende por páginas y más páginas del libro.

Por fin llega el día en que queda terminada y habitable la primera parte de la ciudad subterránea, levantada en un plazo muy corto a pesar de estar construida con los mejores materiales, con elegancia y hasta con lujo. Se detalla su urbanismo, de dos calles paralelas de kilómetro y medio de largo, por las que se deslizan vehículos giroscópicos apoyados en un solo rail; por su canal navegan los barcos e incluso su cielo lo surca una pequeña flotilla aérea. Mientras que el París de arriba está rodeado por una inmensa fosa común, el de abajo lo está por campos cultivables, económicamente regados por niebla de vapor de agua. A estas calles, llamadas Bulevar de los Italianos y Avenida Richelieu, dan las fachadas de mil casas idénticas, que están separadas de diez en diez por una huerta-jardín que proporciona legumbres y donde crecen los árboles frutales. Los edificios públicos están ubicados en la Plaza de la Concordia y son singulares: un esquema clásico de urbanismo utópico.

Y arranca la utopía, que se narra encerrada en un París aislado, donde existe escasa información de provincias y ninguna del extranjero, en una novela que por unas páginas pierde acción para ganar en discursos. No va a durar mucho.

Poco a poco -es un decir, porque todo transcurre a un ritmo vertiginoso- se termina la construcción de la ciu- 
dad y se excavan túneles que alcanzan las otras ciudades que se han ido construyendo y que llegan a comunicar el país entero: todos se han instalado bajo tierra y han buscado después a sus vecinos. El aislamiento ha hecho surgir brotes independentistas que, en la situación que se vive, no pasan de testimoniales. Por su parte los zootauros continúan atacando por las noches en la superficie, que está materialmente arrasada, pero van dejando de causar víctimas humanas en una población que ya no podría soportarlo, pues ha disminuido de un modo dramático.

Después se atraviesan las fronteras y se visitan poblaciones subterráneas del extranjero, donde siempre se dedican largos pensamientos nostálgicos a la ciudad perdida: "¿Qué es Roma sin el Coliseo?" Y lo mismo sucede con España, en San Sebastián, Sevilla o Madrid, aunque en la capital se invita a los viajeros a presenciar una corrida de toros bajo un sol artificial.

El autor va pasando de la nostalgia al pesimismo: él lo ha puesto todo de su parte pero sus personajes no han respondido como esperaba. En París muchos obreros movilizados han sido despedidos al terminar las tareas para que lo fueron y están sin trabajo, la vida se encarece por días y la mayoría de las personas ha perdido la esperanza y el ánimo. Los extremistas de derecha e izquierda explotan el descontento para comportarse de modo cada vez más airado, dando lugar a una revolución social que termina ahogada en sangre. $Y$ cosa parecida se sabe que ha ocurrido en otras ciudades subterráneas. La utopía se va desvaneciendo al no haber igualdad ni justicia y sí una autoridad que, legitimada en principio por la Asamblea y, por más que pese a quien la detenta, se ha convertido en un poder personal sustentado por la fuerza.

"Las utopías psicológicas y filosóficas del siglo XX", estableció Frank Manuel ${ }^{9}$, "abordan el problema de la organización social como un conflicto que está incrustado en la naturaleza biológica del hombre. Son en su mayoría anti-utopías o distopías" y La catástrofe no es la excepción. La novela puede leerse de un modo superficial que sólo atienda a la aventura, que no es poca, pero no lo es todo. "¿Cómo hacéis huelga si la fábrica está colectivizada y ya no tenéis patronos?", clama el jefe a los obreros. Quizá porque hay jefes... El autor acepta resignadamente que sigue habiendo clases sociales, ricos y pobres, explotadores y explotados.
En otras ciudades francesas triunfa la revuelta social y se arría de las Casas de la Villa la enseña tricolor para izar la bandera roja, aunque, una vez más, lo que se detalla son los acontecimientos de París, donde se produce una batalla campal que dura varios dias, en los que la multitud se arma asaltando los arsenales, se lucha casa por casa y barricada por barricada y una interrupción del suministro de energía eléctrica deja la ciudad sin ventilación y sin luz cerca de veinticuatro horas. Cuando las fuerzas gubernamentales sofocan la revuelta, el París subterráneo está seriamente dañado y, por segunda vez en su corta historia, lleno de cadáveres.

Se reconstruye con menos ilusión que cuando se construyó por primera vez y se despachan fuerzas militares a las ciudades en que hay que restablecer la situación. Sólo Lyon y Lille se resisten y han de ser sometidas por la fuerza, reponiéndose el poder central.

"La Francia subterránea volvió a su vida apagada y gris. Los días transcurrian monótonos y sin alegría... Las gentes trataban de adaptarse a las condiciones de la existencia subterránea, ahogando en sus corazones la nostalgia. Y al propio tiempo que los corazones, se empañaban las facultades de la inteligencia, parecía faltar espacio para que se desenvolvieran... Por todas partes reinaba una profunda apatía. Muchas gentes abandonaron por completo sus ocupaciones y durante días enteros iban de una a otra parte o se quedaban en sus casas sin saber qué hacer, indiferentes..."

Aumentan de modo incontrolable las enfermedades mentales, hasta convertirse en un serio problema, y también las físicas, como la tuberculosis. La mortalidad alcanza porcentajes aterradores, especialmente entre los niños y con una natalidad que hay que entender ya reducida. Muchos vuelven desesperados a la superficie para ser víctimas de los zootauros.

La utopía se ha convertido en una horrible distopía. La tierra parece reclamar que, si hasta entonces sólo habian encontrado reposo bajo ella los muertos, así siga siendo en el futuro, pero no existe alternativa: los países que no han construido ciudades subterráneas han visto su población reducida a límites cercanos a su extinción.

Y, aquí llegados, vuelve la aventura al aparecer Juan Granadier, un antiguo catedrático de Física de la Universidad de París que, considerando que sus ojos son el único pun-

ARBOR Vol. 187747 enero-febrero [2011] 183-194 ISSN: 0210-1963

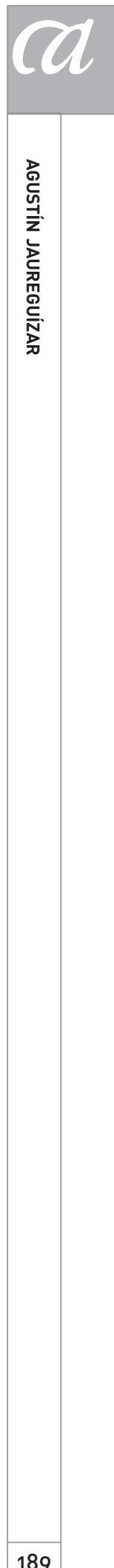


to vulnerable de los zootauros, ha ideado unos campos magnéticos que los dejarán ciegos cuando los atraviesen. Después, privados del sentido de la orientación, terminarán por estrellarse, como aquél que lo hizo contra la catedral de Nôtre-Dame.

Se fabrican electromagnetos gigantes que se montan durante el día sobre los soportes que se han construido. La curiosidad puede más que el miedo y, a más de periodistas y fotógrafos, muchas personas acuden a presenciar el experimento. Tarda en llegar el primer zootauro que, cuando atraviesa el campo, se altera nerviosamente, aunque termina por remontar el vuelo ante el desencanto de la multitud. Mas a poco llega la noticia de que ha caído agonizante en las afueras de Liverpool: es una fecha tan significativa como la del Primero de Mayo. Al día siguiente caen dos más, uno en las costas noruegas y otro en Lanjarón, en Granada.

En días sucesivos varios zootauros más son atrapados en las redes invisibles, dejando de atacar París, de modo que los países adelantados instalan campos y campos magnéticos que los ahuyentan. En los más atrasados, los aborígenes miran con un sentimiento de fatalismo desesperado a los monstruos, cuando no de veneración religiosa rayana en la abyección, y agotados, hambrientos y sumidos en la más negra miseria, se oponen a quienes pretenden instalar los campos, hasta que son sometidos por la fuerza. Un día ya no hay zootauros, que nunca regresarán a la Tierra y jamás se volverá a saber de ellos.

La novela, reitero, admite una lectura superficial que sólo se detenga en la aventura, que es bastante, y otra más profunda, que atienda a las ideas que hay detrás de este ex revolucionario preocupado o desencantado. Es notable para su época y sólo cabe ponerle un pero menor, el tempo: lo que sucede en un mes debería ocurrir en seis.

Con arreglo a las diferencias en principio establecidas, la amenaza de extinción de la Humanidad no proviene de sus actos, sino de una catástrofe exterior, una raza alienígena hostil. No por eso se deja de juzgar a la sociedad, ya que la deseada utopía fracasa y la nueva sociedad parece que va a ser la misma que había y no otra de valores superiores, no se dará la utopía.

Existe una novela también interesante, Las confesiones de Cayac-Hamuaca ${ }^{10}$, ubicada en un mundo futuro social y geopolíticamente distinto, en que la Humanidad sí llega a su completa extinción porque no puede enfrentarse a fuerzas naturales que la sobrepasan. Su diferencia singular con las narraciones más frecuentes no radica en los seres humanos, sino en la Tierra misma. En la antes citada Earth abides, que es su primera muestra, la Tierra resiste -mejor que permanece- y lo que falla es la masa crítica de población capaz de sostener la civilización. Los objetos funcionales, por ejemplo, pasan a ser míticos, lo que culmina en el antológico pasaje final en que el abuelo moribundo otorga un mudo testamento al entregar a uno de sus descendientes el martillo, que es ya sólo el símbolo del poder.

En la igualmente mencionada La carretera, en cambio, la Tierra no resiste, falla como soporte vital del hombre, no hay sol, no hay luz, no hay fauna ni flora. Cuando el padre y el hijo penetran en una granja y encuentran ahorcados en el granero a sus dueños, la mujer y el marido se colgaron cuando dejó de haber cosechas y se comieron las últimas simientes. El testamento final va a ser no menos hermoso, pero sí muy distinto.

Las confesiones está en la línea de La carretera, tampoco hay sol y la Tierra falla como soporte vital del hombre. Es obra de un autor nacido en España, aunque sus padres fueran franceses, y pasó, además, buena parte de su vida fuera de España, como virtual ciudadano de otros países. Tal autor fue un personaje relevante y en este su primer libro apunta ya preocupaciones políticas y sociales que nunca le abandonarán en su posterior literatura de compromiso. En cualquier caso, hoy es una novela tan olvidada como la anterior.

Es una novela laica de un absoluto fin de los tiempos en un Apocalipsis secular del que no se salva nadie. Está escrita por José (Andrés) Lión Dépêtre (Saulnier de Guilhen), cuyo padre, compañero de Eiffel, vino a construir ferrocarriles en España. Nació en Valladolid el 26 de septiembre de 1893 y tuvo una vida apasionante, ligada a la de un hermano veintiún años mayor que él. Ingresó en la carrera diplomática en 1922 y fue destinado sucesivamente a Berlín, a Buenos Aires como secretario de embajada a las órdenes de Ramiro de Maeztu, Amberes, Santos (Brasil), Sofía (Bulgaria), Paris y Méjico, donde fue agregado militar del Gobierno de la República para este país y Centroamérica durante la guerra civil española, tras la cual fue apartado del servicio 
por "muy rojo", "no adherido" y "colaborador activo con el gobierno marxista", exilándose en su último destino.

Se divorció de la esposa con la que había tenido un hijo, que murió en 1952 pilotando una avioneta, y se casó en segundas nupcias con una mejicana, con la que tampoco llegó hasta el fin de sus días, de la que en 1946 tuvo otro hijo varón, el escritor y cineasta Álvaro Lión-Dépetrê. Ese mismo año fue a París como ministro plenipotenciario del Gobierno de la República, todavía con la esperanza de que los Aliados acabasen con el régimen franquista.

Con el citado Gobierno en el exilio obligado a reducir gastos, en situación económica precaria, siguió escribiendo en Méjico hasta que publicó un libro no grato a su gobierno, recibiendo entonces el providencial encargo del Presidente Arbenz de Guatemala de fundar y dirigir la Escuela Diplomática de aquel pais. Depuesto Arbenz, volvió por un tiempo a Méjico $y$, desmoralizado por la muerte de su primer hijo y el devenir de la política, un año después de la amnistía de 1952 regresó definitivamente a España.

Su nombre se vio en varios periódicos españoles y en el francés Le Monde, firmando con frecuencia la famosa tercera de $A B C$. Fundó y dirigió la Escuela Especial de Secretariado María Borkowska y se jubiló en 1963, falleciendo en Alcalá de Henares, por lo que he oído tristemente solo en una residencia de ancianos, en diciembre de 1976: tuvo tiempo de ver morir a Franco.

De vocación literaria, gran conversador y extraordinario cazador, en los primeros años 30 publicó en Madrid la novela que reseño, otra titulada $\mathrm{Y}_{0}$, leproso y el libro $\mathrm{Ca}$ cerías en Europa y América, a las que ya digo que era muy aficionado: participó en más de una de dimensiones colosales. Durante su estancia en Méjico publicó algún libro de carácter histórico, en particular el problemático La tragedia de Méjico"1. Ya en Guatemala, el Ministerio de Educación Pública editó un ensayo suyo sobre la influencia reciproca de las literaturas francesa y española. De nuevo en Madrid, en los años 60 dio a la imprenta dos útiles colecciones de respuestas a los temas de Literatura y Arte del programa de oposiciones a varios Ministerios y su libro postrero fue Chispazos y cicatrices ${ }^{12}$.

Las confesiones se inicia con una "Advertencia" preliminar en la que se presenta al lector a Cayac-Hamuaca, cacique de los indios bororós, una tribu salvaje que habita en la frontera entre Brasil y Colombia. Este cacique, que sabe que cuando muera su espíritu se reencarnará en el español Juan Antonio Reguera, cae una noche en trance y en un castellano perfecto revela el porvenir al autor.

Un porvenir en que aparece Reguera como protagonista y comienza en el otoño del año 2082. El mundo se presenta dividido en una Federación de Estados Europeos de régimen neo-comunista, unas Repúblicas Socialistas Chino-japonesas dominadas por los nipones y unos Estados Unidos imperialistas que han expandido su territorio hasta conquistar América Central en una guerra en que los gases más tóxicos y el rayo artificial eléctrico mataron por millones, el rayo a enormes distancias.

El clima de la Tierra ha cambiado radicalmente en los últimos cincuenta años, pues el planeta se está enfriando cada vez más deprisa porque el sol se está apagando y su extinción es cosa de poco. Regiones enteras son ya inhabitables y unas gentes se desplazan a los países cercanos al Ecuador y otras perecen en mayor número.

También las costumbres han cambiado mucho desde que la mujer alcanzó su completa liberación sexual. La natalidad ha descendido de tal modo que en algunos paises se exigió de las mujeres aptas para la procreación que se apareasen con hombres sabios, artistas o atletas. En otros se obligó a toda mujer sana a tener al menos un hijo, que después mantendría el Estado. Y existían celosos voluntarios vigilantes in situ de que los apareamientos tuvieran lugar debidamente. El libro, una vez expuesto un tema principal que pronto se agota, se entretiene en la anécdota.

Han ido pasado los años y en el 2082 ya nadie se preocupa más que del frío. Como cabría esperar, hay quienes exhortan a prepararse para el inminente paso al más allá, aunque la mayoría de las gentes se entrega al placer de modo desenfrenado. Las religiones tradicionales han sido sustituidas por el neo-espiritismo, por más que no se haya conseguido que los espíritus revelen cómo es realmente el otro mundo, es el Gran Secreto.

No falta el enredo amoroso. El acomodado madrileño Juan Antonio Reguera, de treinta años de edad, está perdidamente enamorado de Mari Luz Montero Villares, de dieciocho primaveras, perteneciente a una religiosa familia

ARBOR Vol. 187747 enero-febrero [2011] 183-194 ISSN: 0210-1963

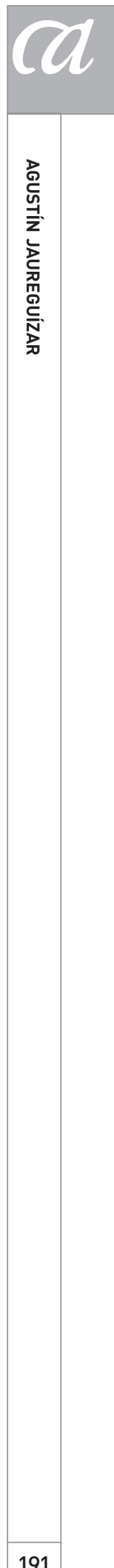


castellana de rancio abolengo, de las que todavía quedan algunas. Su madre es de las que sólo piensan en disponerse para la muerte cercana, que considera justo castigo divino y necesaria purificación y no quiere ni oír hablar de matrimonios en esas circunstancias.

Cuando todavía resta algo de orden, los europeos pudientes emigran a Río de Janeiro, la ciudad más cálida del planeta, y así lo hacen tanto Reguera como los Montero Villares, instalándose en hoteles de lujo. Es imposible calefactar tanta casa particular, por lo que la gente se apiña en los hoteles.

Los brasileños del interior, más los emigrantes que llegan de los países vecinos, se instalan a su vez en las afueras de la urbe para morirse de frío, hasta que, como no podía ser menos, estalla la revuelta más sangrienta que se haya visto jamás. Tras verdaderas matanzas, se consigue un equilibrio entre habentes y carentes, con una distribución más equitativa de la energía para todos los supervivientes.

La energía no falta porque se toma de la atmósfera con los aspiradores inventados por un ingeniero español, pero las frutas y las legumbres sí que escasean por el abandono de la agricultura: la gente se mantiene del pescado, que acude en masa a las costas bañadas por las aguas menos frías, y de la caza de los animales que han abandonado su habitat natural en busca de un clima mejor.

Reguera hace una escapada a Madrid, a dónde llega en un trineo tirado por perros, lo que aprovecha el autor para describir una capital de España cubierta por dos metros de nieve, habitada tan sólo por algunos esquimales y españoles "esquimalizados", con un Retiro al que han talado todos sus árboles para hacer leña y un Manzanares poblado por renos, focas, morsas y osos polares. Son páginas dramáticas, bastante conseguidas.

Y la novela, reitero, se pierde en anécdotas, tal la de un amigo del padre de Reguera, de más de sesenta años de edad, que se hace implantar las "glándulas" que ha comprado a un pobre obrero de veintiún años que carece de recursos para mantener a su madre.

Por más que de pasada, insinúa Saiz Cidoncha ${ }^{13}$ para el autor una ideología que no le corresponde, aunque a veces pueda parecerlo. Cuando habla de las modern girls o de la desaparición del recato y el pudor femeninos utiliza ciertamente el lenguaje de un conservador, lo que podría hacer pensar en un rechazo de la situación a que habria llegado la sociedad en el 2082 si a continuación no dijera que este recato y este pudor se consideran desviaciones espirituales o deformaciones psíquico-físicas, al modo de la timidez o la tartamudez.

Su supuesto conservadurismo se acentuaría cuando expone detenidamente el religiosísimo pensamiento de la madre de Mari Luz, si no fuera porque ahora advierte claramente que responde a las creencias de una minoría, pues las religiones tradicionales, a cuyos fieles llama a veces sectarios, casi han desaparecido, sustituidas por el mentado neo-espiritismo. Como un detalle más, cuando se refiere a la mezquita de Córdoba dice que es un templo profanado por el culto cristiano.

Por si fuera poco su trayectoria vital y la imaginación de anécdotas como la de las glándulas trasplantadas, propia de una literatura libertaria ${ }^{14}$, dice que los Estados Europeos, de régimen neo-comunista, componen una gran Confraternidad, con la vida dulcificada y metódicamente dirigida hacia el reparto equitativo de las comodidades, mientras que los Estados Unidos, donde impera el capitalismo salvaje, constituyen un feroz imperio injusto y agresivo.

En lo que tiene razón Saiz Cidoncha, que suele ser un buen guía -casi el único en ocasiones-, es en que se percibe que se trata de una novela escrita en los últimos tiempos de la monarquía, literatura anterior a la proclamación de la República, por más que apareciera después.

Llega un momento en que se hace imposible alimentar a los millones de habitantes de Río, por lo que el gobierno de Brasil concede plenos poderes al canganceiro Euclides Santos para que extermine a los que malviven en los suburbios, gaseando económicamente a los periféricos y electrocutando con un mayor coste a los más interiores, cuyo gaseamiento no podría llevarse a cabo sin poner en peligro la vida de algunos residentes del centro. La población se reduce así en dos terceras partes, con más posibilidades de comer y calentarse para el tercio restante.

Todo es en vano. Cuando la temperatura sigue descendiendo desaparecen los servicios públicos y el dinero pierde todo su valor. No se puede salir a la calle, plagada de cadá- 
veres, y si no aparecen las plagas es porque los cuerpos insepultos están absolutamente congelados. Las gentes han de alimentarse de las reservas que hayan podido acumular en sus hoteles, donde ya no se distinguen los clientes de los antiguos empleados.

Al morir sus padres, Mari Luz se casa con Juan Antonio: alcanzan penosamente una iglesia, pero no llegan a alcanzar a la salida su refugio. $Y$ las páginas finales sólo presentan aterradoras estampas de desolación y muerte, estampas en las que no falta ni la posesión del cadáver desnudo de quien fuera la mujer más bella del mundo por parte de un vagabundo, ni la muerte de Nari Luz en brazos de Juan Antonio tras un único y último beso.

"Y el Sol, moribundo, no era ya sino un disco blanquecino que apenas se destacaba sobre la atmósfera helada, alumbrando el inmenso frigorífico con luz opalina de funeral..."

La Humanidad se extingue por una causa exterior, un fenómeno cósmico que la Tierra no puede enfrentar, aunque no deja de darse un juicio sobre la Humanidad que perece.

\section{NOTAS}

1 Tassin, N. La catástrofe, "novela fantástica", Madrid, Librería Editorial Madrid (Conde de Peñalver, 8), colección Escritores Contemporáneos, 1924, rústica, cubierta de Yuste, 398 pp. en $8 .^{\circ}$ mayor $(19 \times 12 \mathrm{~cm}$.), 5 pta. Está impresa por Sucesores de Rivadeneyra, a veces citados como sus editores.

2 Pedraza Jiménez, Felipe B. y Rodriguez Cáceres, Milagros, Manual de Literatura española, tomo X: Novecentismo y vanguardia. Introducción, prosistas y dramaturgos, Cenit eds., Pamplona, 1991, p. 122.

3 Sólo se menciona una vez en las Obras Completas de Lenin, en una carta de éste a Krestinsky, tomo 54 , p. 22, de la 5. a ed., Moscú, 1965.

4 En un trabajo realizado por Tina Balabanova y Natalia Svéshnikova, amablemente traducido por mi buena amiga Natela Topuria.

5 Hecha la corrección de calendario, la fecha corresponde a la del $50 .^{\circ}$ aniversario de la revolución rusa de febrero de 1917.

6 Marte, el planeta rojo, guarda una cierta relación con la estrella roja de la revolución, con la que más de una vez fue asociado.
7 Al tiempo que la combinación zeppelin-zootauro parece evidente, me apunta el señor Rossiyski que zootauro le suena a mote de colegio, quizá alguno de los compañeros de clase de Tasin fuera asi motejado y le dio la palabra hecha.

8 Mencionaba en otro artículo, el dedicado al "Viaje a Marte de Modesto Brocos", que no hay utopista que no construya sus ciudades con criterios geométricos, lo que se completa con la igualdad de todas las casas. Entre los españoles es así desde Maldonado en su Somnium de 1532 hasta Mella en La Nueva Utopía de 1889.

9 Manuel, Frank, "Hacia una historia psicológica de las utopias", en Utopías y pensamiento utópico, Madrid, Espasa-Calpe, 1982, pp. 104-106.

10 Lión Dépêtre, José, Las confesiones de Cayac-Hamuaca, Madrid, Imprenta de Sáez Hnos. (Martín de los Heros, 61), 1931, rústica, intonso, 169 pp. en $8 .^{\circ}$ marquilla $(19 \times 13 \mathrm{~cm}$.), 5 pta.

11 En la reedición de La tragedia de Méjico que ha publicado en 2009 Akrón en su colección Testimonios, cuenta Álvaro, el segundo hijo de José, que en 1955, cuando un general mejicano vio este libro en el escaparate de una librería de la calle Preciados de
Aceptado: 3 de enero de 2011 
Madrid, sacó la pistola y le descerrajó cinco tiros. El incidente se silenció entonces.

12 He tomado sus datos biográficos del Archivo del Ministerio de Asuntos Exteriores y de la amable colaboración de su sobrino D. Andrés Lión, primero, y algunos más, después, de la Introducción a la citada reedición de La tragedia de Méjico, obra de D. Luis Arias González, quien, al tener conocimiento de este artículo, me puso un amable correo, que agradezco, en que decía que bien merecería este autor una película o una gran biografía.

13 Saiz Cidoncha, Carlos. La ciencia ficción como fenómeno de comunicación y de cultura de masas, tesis doctoral, Madrid, Facultad de Cien- cias de la Información, Universidad Complutense, 1988.

14 También en 1945. El advenimiento del comunismo revolucionario, de Alfonso Martínez Rizo, publicado un año después que Las confesiones, un acaudalado viejo decrépito se convierte en un apuesto joven al hacerse injertar los testículos de un chico que apenas había alcanzado la pubertad. 